\title{
ANALISIS PRODUKSI DAN PENDAPATAN USAHATANI KAKAO DI KECAMATAN TRIENGGADENG KABUPATEN PIDIE JAYA
}

\author{
(Production Analysis And Cocoa Health Income In Kecamatan Trienggadeng Pidie Jaya \\ District)
}

\author{
Irhamna,T. Fauzi ${ }^{1}$, Romano ${ }^{1 *}$. \\ ${ }^{1}$ Program Studi Agribisnis, Fakultas Pertanian, Universitas Syiah Kuala
}

\begin{abstract}
ABSTRAK Tujuan dari penelitian ini adalah untuk mengetahui faktor-faktor yang mempengaruhi produksi usahatani kakao di kecamatan Trienggadeng dan untuk mengetahui tingkat pendapatan petani kakao di Kecamatan Trienggadeng. Lokasi penelitian ini dilakukan di Kecamatan Trienggadeng Kabupaten Pidie Jaya. Lokasi ini ditentukan dengan pertimbangan bahwa Kecamatan Trienggadeng merupakan salah satu sentra produksi kakao di Kabupaten Pidie Jaya. Ruang lingkup penelitian terbatas pada analisis produksi dan pendapatan usahatani kakao di Kecamatan Trienggadeng Kabupaten Pidie Jaya. Populasi dalam penelitian ini adalah seluruh petani yang berusahatani kakao di Kecamatan Trienggadeng, di fokuskan pada tiga desa yang terdiri dari Desa Reuseb, Desa Dee, dan Desa Teumanah. Penentuan ini dilakukan dengan sengaja, dimana tiga desa tersebut merupakan sentral produksi di Kecamatan Trienggadeng. Jumah petani dari 3 desa sebanyak 196 petani. sampel dipilih secara multi stage sampling. Sedangkan besarnya sampel yang digunakan dalam penelitian ini adalah $25 \%$ dari total populasi penelitian yaitu 49 nelayan. Model analisis untuk hipotesis pertama digunakan rumus pendapatan yaitu $\mu=\mathrm{TR}-\mathrm{TC}$ dan untuk hipotesis kedua di gunakan analisis linear berganda. Hasil dari penelitian menunjukkan bahwa modal berpengaruh nyata (signifikan) terhadap produksi usahatani kakao, hal ini dapat dikemukakan bedasarkan hasil uji-t yang menunjukkan $t_{\text {cari }}=2,219>t_{\text {tabel }}=2,014$. Luas lahan berpengaruh nyata (signifikan) terhadap produksi usahatani kakao, hal ini dapat di kemukakan berdasarkan hasil uji-t yang menunjukkan $t_{\text {cari }}$ $=2,127>t_{\text {tabel }}=2,014$. Tenaga kerja berpengaruh nyata (signifikan) terhadap pendapatan usahatani kakao, hal ini dapat di kemukakan berdasarkan hasil uji-t yang menunjukkan $t_{\text {cari }}=2,319>t_{\text {tabel }}=$ 2,014. Modal, luas lahan, tenaga kerja adalah berpengaruh nyata secara serempak terhadap produksi usahatani kakao, dibuktikan dengan nilai $\mathrm{F}_{\text {cari }}=418,300>\mathrm{F}_{\text {tabel }}=2,42$ pada tingkat kepercayaan $95 \%$ $(\alpha=0,05)$. Pendapatan usahatani kakao lebih besar dibandingkan Upah Minimum Provinsi (UMP) yaitu Rp. 2.420.265 sedangkan UMP yang ditetapkan oleh pemerintah Aceh tahun 2016 adalah sebesar Rp. 2.100.000.

Kata Kunci :Produksi, Pendapatan, Petani
\end{abstract}

ABSTRACT The purpose of this study is to determine the factors that affect the production of cocoa farming in Trienggadeng district and to determine the level of income of cocoa farmers in District Trienggadeng. The location of this research was conducted in District Trienggadeng Pidie Jaya District. This location is determined with the consideration that District Trienggadeng is one of cocoa production centers in Pidie Jaya Regency. The scope of the study is limited to the analysis of production and income of cocoa farming in Trienggadeng Sub-district of Pidie Jaya Regency. The population in this study is all farmers who have cacao farms in Trienggadeng Sub-district, focusing on three villages consisting of Reuseb Village, Dee Village, and Teumanah Village. This determination is done intentionally, where the three villages are the central production in District Trienggadeng. There are 196 farmers from 3 villages. samples were chosen in multi stage sampling. While the sample size used in this study is $25 \%$ of the total research population of 49 fishermen. The model of analysis for the first hypothesis used the income formula is $\mu=\mathrm{TR}-\mathrm{TC}$ and for the second hypothesis is used multiple linear analysis. Result of research indicate that capital have significant effect to cocoa farming production, this can be based on t-test which shows $=2,219>$ ttable $=2,014$. Land area significantly (significant) effect on cocoa farming production, it can be suggested based on t-test which shows $=2,127>$ ttable $=2,014$. Workforce has significant (significant) effect to cocoa farming income, it can be suggested based on t-test which shows $=2,319>$ ttable $=2,014$. Capital, 
land area, labor is a significant effect simultaneously on cocoa farming production, evidenced by the value Fcari $=418,300>$ Ftable $=2.42$ at $95 \%$ confidence level $(\alpha=0.05)$. The income of cocoa farming is higher than the Provincial Minimum Wage (UMP) which is Rp. 2.420.265 while the UMP set by the government of Aceh in 2016 is Rp. 2.100.000.

Keywords: Production, Income, Farmer

\section{PENDAHULUAN}

Indonesia merupakan negara produsen ketiga terbesar kakao dunia setelah Evory Coast (Pantai Gading) dan Ghana. Luas areal tanaman kakao Indonesia tercatat seluas 1.4 juta hektar dengan produksi kurang lebih 500 ribu ton pertahun. Pantai Gading yang menempati urutan pertama negara terbesar penghasil kakao memiliki luas areal 1.6 juta hektar dengan produksi sebesar 1.3 juta ton pertahun dan Ghana sebesar 900 ribu ton pertahun (Dirjenbun, 2013).

Provinsi Aceh merupakan salah satu daerah penghasil kakao di Indonesia. Salah satu daerah penghasil kakao di provinsi Aceh yaitu di Kabupaten Pidie Jaya. Pidie Jaya merupakan salah satu penghasil kakao di provinsi Aceh yang hampir di seluruh wilayahnya merupakan penghasil kakao. Pidie jaya merupakan daerah yang memeliki kondisi tanah yang subur dan iklim yang mendukung untuk tanaman kakao. Kecamatan Trienggadeng merupakan salah satu kecamatan penghasil kakao yang ada di kabupaten pidie jaya.

Usahatani kakao di Kecamatan Trienggadeng saat ini masih menghadapi berbagai tantangan diantaranya masih di kelola belum sesuai SOP/petunjuk teknis yang ada. Untuk tingkat produksi masih belum stabil, mutu biji kakao yang masih rendah dikarenakan tempat penjemurannya tidak sesuai standar dimana petani melakukan penjemuran pada alas terpal ataupun dipinggir jalan yang terkontaminasi dengan debu ataupun kotoran lainnya. Serangan organisme pengganggu tanaman (OPT) yang masih tinggi seperti babi hutan, kutu-kutuan, kakao mot/ngengat buah, penggerek buah kakao (PBK). Dari segi modal petani di trienggadeng hanya mengandalkan modal yang di miliki saja, tidak mengajukan pinjaman/kredit usaha ke Bank, sistem informasi pasar yang masih lemah mengakibatkan petani lemah dalam daya tawar harga dengan pedagang sehingga petani harus menerima bagian kecil dari harga penjualan biji. yang merupakan salah satu sentral produksi kakao terbesar dan menjadi tumpuan produksi di Kabupaten Pidie Jaya memiliki karakteristik tersendiri dan juga kondisi alam yang tidak menentu.

Melihat luas lahan dan produksi kakao yang besar di Kecamatan Trienggadeng ternyata masih banyak permasalahan yang dihadapi petani di antaranya ketika panen tiba dengan hasil yang melimpah pendapatan mereka masih sangat kurang dikarenakan hasil panen mereka hanya dijual pada pedagang (tengkulak) lokal yang berada di Kecamatan Trienggadeng dengan harga yang murah, permasalahan lainya adalah belum adanya suatu instansi yang memfasilitasi dalam pendistribusian atau memasarkan hasil produksi kakao sehingga mengakibatkan belum meratanya pendapatan yang diterima oleh petani.

Tujuan di laksanakan penelitian ini untuk mengetahui faktor-faktor yang mempengaruhi produksi usahatani kakao di kecamatan Trienggadeng dan untuk mengetahui tingkat pendapatan petani kakao di Kecamatan Trienggadeng.

\section{METODE PENELITIAN}

Lokasi penelitian ini dilakukan di Kecamatan Trienggadeng Kabupaten Pidie Jaya. Lokasi ini ditentukan dengan pertimbangan bahwa Kecamatan Trienggadeng merupakan salah satu sentra produksi kakao di Kabupaten Pidie Jaya. Objek penelitian adalah petani

Analisis produksi dan pendapatan usahatani kakao di Kecamatan Trienggadeng Kabupaten Pidie Jaya 201 (Irhamna, T. Fauzi , Romano,)

Jurnal Ilmiah Mahasiswa Pertanian Unsyiah, Vol 3, No 4, November 2018: 200-205 
kakao di Kecamatan Trienggadeng Kabupaten Pidie Jaya. Ruang lingkup penelitian terbatas pada analisis produksi dan pendapatn usahatani kakao di Kecamatan Trienggadeng Kabupaten Pidie Jaya.

Populasi dalam penelitian ini adalah seluruh petani yang berusahatani kakao di Kecamatan Trienggadeng, di fokuskan pada tiga desa yang terdiri dari Desa Reuseb, Desa Dee, dan Desa Teumanah. Penentuan ini dilakukan dengan sengaja, dimana tiga desa tersebut merupakan sentral produksi di Kecamatan Trienggadeng. Jumah petani dari 3 desa sebanyak 196 petani. sampel dipilih secara multi stage sampling. Sedangkan besarnya sampel yang digunakan dalam penelitian ini adalah $25 \%$ dari total populasi penelitian yaitu 49 nelayan.

Data yang telah dikumpulkan dilapangan selanjutnya diolah dan ditabulasikan, kemudian dipindahkan dalam bentuk tabel sesuai dengan kebutuhan analisis penelitian. Sesuai dengan hipotesis yang telah dirumuskan diatas, maka digunakan rumus pendapatan untuk hipotesis pertama dan analisis regresi linear berganda untuk hipotesis kedua.

\section{HASIL PENELITIAN DAN PEMBAHASAN}

Besarnya keuntungan yang diperoleh usahatani kakao di Trienggadeng yang dihitung dalam penelitian ini sangat berhubungan dengan biaya penggunaan sarana produksi dan biaya penggunaan tenaga kerja. Untuk mengetahui pendapatan rata-rata per hektar usahatani kakao di Kecamatan Trienggadeng dapat digunakan rumus sebagai berikut :

$$
\begin{aligned}
\Pi= & \mathrm{TR}-\mathrm{TC} \\
& =\text { Rp. } 21.600 .000-\text { Rp. } 9.498 .674 \\
& =\text { Rp. } 12.101 .326
\end{aligned}
$$

Berdasarkan pengujian hipotesis 1, pendapatan rata-rata per hektar usahatani kakao di Trienggadeng yang diperoleh petani yaitu sebesar Rp. 12.101.326 Ha/musim panen.

Pendapatan bersih adalah selisih antara penerimaan dengan biaya produksi. Secara keseluruhan rata-rata pendapatan bersih usahatani kakao per petani per hektar dalam satu musim panen dan per bulan di daerah penelitian dapat dilihat pada Tabel 11 berikut :

Tabel 1. Pendapatan Bersih Rata-rata per Petani per Hektar per Musim Panen dan per Bulan di Daerah Penelitian

\begin{tabular}{cccccc}
\hline $\mathbf{N}$ & Uraian & & & Per Petani (Rp) & Per Hektar (Rp) \\
\hline 1 & $\begin{array}{c}\text { Pendapatan } \\
\text { musim panen) }\end{array}$ & Bersih & $(\mathrm{Rp} /$ & 12.101 .326 & 12.101 .326 \\
\hline 2 & $\begin{array}{c}\text { Pendapatan } \\
\text { bulan) }\end{array}$ & Bersih & $(\mathrm{Rp} /$ & 2.420 .265 & 2.420 .265 \\
\hline
\end{tabular}

Sumber : Data Primer 2018 (diolah)

Bedasarkan tabel 1, dapat diketahui bahwa secara kesuluruhan rata-rata pendapatan bersih usahatani kakao per petani per musim panen adalah sebesar Rp. 12.101.326, sehingga rata-rata pendapatan bersih usahatani kakao per petani perbulan adalah Rp 2.420.265 dan pendapatan bersih rata-rata per hektar per bulan.

Bila dibandingkan dengan Upah Minimum Provinsi (UMP) yaitu sebesar Rp. 2.100.000 / per bulan maka rata-rata pendaptan bersih usahatani kakao per petani per bulan di daerah penelitian lebih besar dari Upah minimum Provinsi (UMP) per bulan.

Analisis produksi dan pendapatan usahatani kakao di Kecamatan Trienggadeng Kabupaten Pidie Jaya 202 (Irhamna, T. Fauzi , Romano,) 
Tabel 2. Hasil Analisis Regresi Pengaruh Produksi, luas Lahan, Tenaga Kerja, Usahatani Kakao.

\begin{tabular}{|c|c|c|c|c|c|c|}
\hline & $\begin{array}{l}\text { Variabel } \\
\text { Bebas } \\
\end{array}$ & $\begin{array}{l}\text { Koefesien } \\
\text { Regresi }\end{array}$ & $\mathbf{T}_{\text {cari }}$ & $\begin{array}{ll}\text { kansi } & \text { Signifi } \\
\end{array}$ & bel & $\mathbf{T}_{\mathbf{t a}}$ \\
\hline a) & (Konstant & 296.196 & $\begin{array}{ll} & 11.76\end{array}$ & 0.000 & \multirow{4}{*}{14} & \multirow{4}{*}{2,0} \\
\hline & Modal & 4.779 & 2.219 & 0.032 & & \\
\hline Lahan & Luas & 195.172 & 2.127 & 0.039 & & \\
\hline Kerja & Tenaga & 7.789 & 2.319 & 0.025 & & \\
\hline \multicolumn{7}{|c|}{$F_{\text {cari }}=418.300$} \\
\hline \multicolumn{7}{|c|}{$F_{\text {tabel }}=2,42$} \\
\hline \multicolumn{7}{|c|}{$R^{2}=0,965$} \\
\hline
\end{tabular}

Sumber : Data Primer 2018 (diolah)

Dari tabel diatas dapat persamaan regresi sebagai berikut :

$\hat{\mathbf{Y}}=\mathbf{2 9 6 . 1 9 6}+4.7792 \mathrm{X}_{1}+\mathbf{1 9 5 . 1 7 2}_{2}+\mathbf{7 . 7 8 9}_{3}$

Dari persamaan tersebut dapat dijelaskan apabila modal, luas lahan dan tenaga kerja diasumsikan berada pada keadaan yang konstan maka besarnya produksi usahatani kakao adalah sebesar 296,196 kg.

Untuk melihat secara statistik tingkat keberartian (signifikansi) koefisien (pengaruh dari masing-masing variabel bebas) maka diuji terpisah (parsial) antara variabel bebas terhadap variabel terikat dengan uji t. Hasil pengujian secara parsial bagi setiap variabel dengan tingkat kepercayaan sebesar $95 \%$ (taraf nyata $(\alpha)=5 \%$ ) adalah sebagai berikut :

Nilai koefesien modal adalah sebesar 4,779 menunjukkan bahwa terdapat pengaruh positif antara modal dan pendapatan. Dengan demikian, setiap kenaikan 1000 rupiah modal kakao maka akan menaikkan produksi sebesar 4,779 Kg. Uji-t statistik, hasil analisis terhadap modal $t_{\text {cari }}=2.219$ sedangkan $t_{\text {tabel }}=2,014$, hal ini menunjukkan bahwa $t_{\text {cari }}>t_{\text {tabel, }}$, yang berarti hipotesis alternatif diterima dan hipotesis nol ditolak. Dengan demikian modal berpengaru nyata (signifikan) terhadap produksi usahatani kakao.

Nilai koefesien luas lahan 195,172 menunjukkan bahwa terdapat hubungan positif antara luas lahan dan produksi. Hal ini menunjukkan setiap kenaikan 1 Ha luas lahan maka akan menaikkan produksi sebesar 195,172 Kg. Pada uji-t statistik, hasil analisis terhadap luas lahan $t_{\text {cari }}=2.127$ sedangkan $t_{\text {tabel }}=2,014$, hal ini menunjukkan bahwa $t_{\text {cari }}>t_{\text {tabel, }}$ yang berarti hipotesis alternatif diterima dan hipotesis nol ditolak. Dengan demikian luas lahan berpengaruh nyata terhadap produksi usahatani kakao.

Untuk tenaga kerja nilai koefisiennya adalah 7,789 menunjukkan bahwa terdapat pengaruh positif antara tenaga kerja dan produksi usahatani kakao. Hal ini menunjukkan bahwa setiap kenaikan 1 HKP tenaga kerja maka akan meningkatkan produksi sebesar 7,789 Kg. Pada uji-t statistik, hasil analisis terhadap tenaga kerja didapat hasil $t_{\text {cari }}=2.319$ dan sedangkan $t_{\text {tabel }}=2,014$, hal ini menunjukkan bahwa $t_{\text {cari }}>t_{\text {tabel, yang berarti hipotesis }}$ alternatif diterima dan hipotesis nol ditolak. Dengan demikian tenaga kerja berpengaruh nyata terhadap produksi usahatani kakao.

Hasil pengujian secara serempak (uji-F) anatara variabel terikat dengan variabel bebas diperoleh nilai $\mathrm{F}_{\text {cari }}=418.300$ sedangkan $\mathrm{F}_{\text {tabel }}=2,42$ pada tingkat kepercayaan $95 \%$ $(\alpha=0,05)$ dengan ketentuan $\mathrm{F}_{\text {cari }}>\mathrm{F}_{\text {tabel }}$ dimana hipotesis alternatif diterima dan hipotesis

Analisis produksi dan pendapatan usahatani kakao di Kecamatan Trienggadeng Kabupaten Pidie Jaya 203 (Irhamna, T. Fauzi , Romano,) 
nol ditolak. Dengan demikian modal, luas lahan dan tenaga kerja secara serempak berpengaruh nyata terhadap produksi usahatani kakao.

Selanjutnya untuk hasil pengujian koefisien alternatif $\left(\mathrm{R}^{2}\right)$, di peroleh nilai sebesar 0,965. Artinya, bahwa keeratan hubungan antara variabel terikat dan variabel bebas adalah sebesar 96,5\% yang dapat dijelaskan oleh ke-tiga variabel bebas di dalam model persamaan ini. Sisanya sebesar 3,5\% di jeaskan oleh faktor-faktor diluar model persamaan ini.

\section{Kesimpulan}

\section{SIMPULAN DAN SARAN}

Bedasarkan hasil penelitian dan pembahasan, maka dapat diambil kesimpulan sebagai berikut :

1. Modal berpengaruh nyata (signifikan) terhadap produksi usahatani kakao, hal ini dapat dikemukakan bedasarkan hasil uji-t yang menunjukkan $t_{\text {cari }}=2,219>t_{\text {tabel }}=2,014$. Luas lahan berpengaruh nyata (signifikan) terhadap produksi usahatani kakao, hal ini dapat di kemukakan berdasarkan hasil uji-t yang menunjukkan $t_{\text {cari }}=2,127>t_{\text {tabel }}=$ 2,014. Tenaga kerja berpengaruh nyata (signifikan) terhadap pendapatan usahatani kakao, hal ini dapat di kemukakan berdasarkan hasil uji-t yang menunjukkan $\mathrm{t}_{\text {cari }}=2,319$ $>\mathrm{t}_{\text {tabel }}=2,014$. Modal, luas lahan, tenaga kerja adalah berpengaruh nyata secara serempak terhadap produksi usahatani kakao, dibuktikan dengan nilai $\mathrm{F}_{\text {cari }}=418,300>$ $\mathrm{F}_{\text {tabel }}=2,42$ pada tingkat kepercayaan $95 \%(\alpha=0,05)$.

2. Pendapatan usahatani kakao lebih besar dibandingkan Upah Minimum Provinsi (UMP) yaitu Rp. 2.420.265 sedangkan UMP yang ditetapkan oleh pemerintah Aceh tahun 2016 adalah sebesar Rp. 2.100.000.

\section{Saran}

1. Untuk meningkatkan produksi dapat dilakukan dengan mengoptimalkan teknik penanaman dan pemeliharaan yang baik. Peningkatan produksi tidak hanya diperoleh dari luas lahan yang meningkat, tetapi juga dipengaruhi oleh modal dan tenaga kerja. Karena luas lahan yang luas tidak menjamin peningkatan produksi jika pengolahan tanah dan pemeliharaan serta pengalokasian tenaga kerja tidak optimal, efektif dan efesien.

2. Untuk meningkatkan pendapatan petani kakao diharapkan pemerintah supaya membantu para petani untuk membuat koperasi atau lembaga pemasaran (Terminal Agribisnis) agar dapat meningkatkan pendapatan petani di Kecamatan Trienggadeng.

\section{DAFTAR PUSTAKA}

Agus Sudibyo. 2012. Peran Cokelat Sebagai Produk Pangan Derivatkakao. Algifari. 2000. Analisis Regresi, Teori, Kasus \& Solusi. BPFE UGM. Yogyakarta.

Anggi Arga. 2010. "Masalah Usahatani dan Faktor-Faktor yang Mempengaruhi Usahatani”. Selawesi Tenggara.

Arief Nurdiansyah. 2015. “Analisis Pendapatan Dan Pemasaran Kakao Di Kecamatan Sekampung Udik. Kabupaten Lampung Timur.

Arikunto. 2006. Prosedur Penelitian Suatu Pendekatan Praktek. PT. Rineka Cipta. Jakarta. Badan Pusat Statistik. 2015. Kabupaten Pidie Jaya Dalam Angka. Provinsi Aceh.

Analisis produksi dan pendapatan usahatani kakao di Kecamatan Trienggadeng Kabupaten Pidie Jaya 204 (Irhamna, T. Fauzi , Romano,) 
Bambang. 2012. Meningkatkan Daya Saing Perkebunan Kakao Rakyat Melalui Penguatan Kelembagaan Petani "Lembaga Ekonomi Masyarakat (LEM) Sejahtera. LEM Sejahtera Sulawesi Tenggara. Kendari.

Daniel. 2002. Pengantar Ekonomi Pertanian. Bumi Aksara, Jakarta.

Dewi sahara. 2004. "Faktor-faktor yang mempengaruhi tingkat keuntungan usahatani kakao. Sulawesi Tenggara.

Direktorat Jenderal Perkebunan Kementerian Pertanian 2013. Luas lahan kakao. Sambutan Direktur Jenderal Perkebunan dalam acara Musyawarah Nasional II Asosiasi Petani Kakao Indonesia. Jakarta.

Gujarati. 1999, Ekonometrika Dasar, Erlangga. Jakarta.

Gaspersz, Vincent. 1997. Manajemen Kualitas. PT. Gramedia Pustaka Utama. Jakarta.

Gumbira. 2001. Manajemen Agribisnis. Jakarta: Penerbit Ghalia Indonesia.

Gustiyana, H. 2003. Analisis Pendapatan Usahatani untuk Produk Pertanian.

Salemba empat: Jakarta.

Hadisapoetra. 1979. Biaya dan Pendapatan dalam Usahatani. Departemen Ekonomi Pertanian Universitas Gajah Mada. Yogyakarta.

Hernanto. 1994. Ilmu Usahatani. Penebar Swadaya. Jakarta.

Irsad Asrar et al. 2015. "Analisis produksi usahatani kakao di Desa Masari Kecamatan Parigi Selatan ". Kabupaten Parigi Moutong.

Irving CK Putri. 2013. Analisis Pendapatan Petani Kakao di Kabupaten Parigi-Moutong. Jurnal EMBA. Manado.

Jauda, Rosneni La. 2016. Analisis Pendapatan Usahatani Kakao Di Desa Tikong, Kecamatan Taliabu Utara, Kabupaten Kepulauan Sula. Jurnal. Manado.

Kartasapoetra. 1987. Pengantar Ekonomi Produksi Pertanian. Bina Aksara. Jakarta.

Kotler. 1998. Manajemen Pemasaran: Analisis, Perencanaan, Implementasi dan Kontrol. PT. Prenhallindo. Jakarta.

Mubyarto. 1989. Pengantar Ekonomi Pertanian. Edisi Ke-tiga, LP3S. Jakarta.

Mulyadi. 2005. Akuntansi Biaya, Edisi kelima, Cetakan ketujuh. Akademi Manajemen Perusahaan YKPN. Yogyakarta.

Mulyarto. 1999. Pembangunan: Dilema dan Tantangan. Pustaka Pelajar. Yogyakarta.

Putu Arimbawa. 2013. "Peran kelembagaan agribisnis usaha tani kakao". Kolaka Timur.

Soekartawi. 1995. Analisis Usahatani. Raja Grafindo Persada. Jakarta.

Soekartawi. 2002. Analisis Usaha Tani. UI Press. Jakarta.

Sukirno. 2008. Pengantar Teori Mikro ekonomi. Raja Grafindo Persada. Jakarta.

Suratiyah. 2006. Ilmu Usahatani. Penebar Swadaya. Jakarta.

Suryani, D dan Zulfebriansyah. 2007. Komoditas Kakao : Potret Dan Peluang Pembiayaan. $\begin{array}{llll}\text { Economic } & \text { Review } & \text { No. } & 210\end{array}$ http://www.bni.co.id/Portals/0/Document/Komoditas\%20Kakao.pdtf.

Widya, Y. 2008. Budidaya bertanam Cokelat. Tim Bina karya Tani. Bandung.

Analisis produksi dan pendapatan usahatani kakao di Kecamatan Trienggadeng Kabupaten Pidie Jaya 205 (Irhamna, T. Fauzi , Romano,)

Jurnal Ilmiah Mahasiswa Pertanian Unsyiah, Vol 3, No 4, November 2018: 200-205 